\title{
Countercurrent index determination for the recuperative heat exchangers
}

\author{
GUŽELA Štefan ${ }^{*}$, DZIANIK František ${ }^{1}$ \\ ${ }^{1}$ Slovak University of Technology in Bratislave, Faculty of Mechanical Engineering, Institute of Process \\ Engineering, Námestie slobody 17, 81231 Bratislava 1, Slovakia, e - mail: stefan.guzela@stuba.sk
}

\begin{abstract}
The recuperative heat exchangers are an important part of the industrial plants. There are a number of such heat exchangers that differ in the arrangement of the streams. The knowledge of the flow arrangement of the streams is very important from a point of view of the heat exchangers calculations. There are various calculation methods, but only one takes into account the flow arrangement of the streams directly. The quantity that takes this into account is called the countercurrent index. The article deals with the determination of this quantity for a given recuperative heat exchanger.
\end{abstract}

KEYWORDS: heat exchanger calculation, countercurrent index, operating characteristic, number of transfer units, heat exchanger efficiency

\section{Introduction}

There are various calculation methods of the recuperative heat exchangers with two inlet and two outlet streams. Methods LMTD [1], $\varepsilon$-NTU [2], and $\theta$-NTU [3] belong to the standard methods. All these methods use dimensionless quantities to describe heat exchangers. Each of the mentioned methods defines one key variable. In the case of LMTD method it is the quantity $F$, in the case of $\theta$-NTU method it is the quantity $\theta$, and in the case of $\varepsilon$-NTU method it is the quantity NTU. Without the knowledge of the key variable, it is not possible to perform the calculation of the heat exchanger.

There are also other methods but these do not define a new key variable. The interesting method is Roetzel-Spang method [4]. The novelty of this method lies in the graphical interpretation of the dimensionless quantities. This method also makes it possible to show in one diagram the recuperative heat exchanger which is characterized by the asymmetrical flow arrangement of the streams.

$\varepsilon$-NTU method is considered to be the most preferred calculation method of the recuperative heat exchangers. The reason is the fact that the heat exchanger calculation can be done without the need for iteration. This applies not only to the design calculation but also to the checking calculation of the heat exchanger. $\varepsilon$-NTU method works with the functional dependence $\varepsilon_{i}=P_{i}=\mathrm{f}\left(\mathrm{NTU}_{i}, R_{i}\right)$ by means of which the experimental data are evaluated. These are then presented in the literature by the graphs or by the analytical dependencies, e.g., [5-11].

Each heat exchanger is generally characterized by a different functional dependence $P_{i}=\mathrm{f}\left(\mathrm{NTU}_{i}, R_{i}\right)$. This is due to the fact that the heat exchangers differ from each other in the configuration - flow arrangement. This fact takes into account the countercurrent index $\left(p_{p}\right)$ [12]. The aim of this paper is to point out that the heat exchanger can also be characterized by the variable $p_{p}$, including how to determine the value of this variable for a given recuperative heat exchanger. 


\section{Analytical dependencies for determining the countercurrent index}

The dimensionless variables (including the key variables) used to describe the heat exchangers are clearly interrelated. This relationship according to [13] expresses the following equations:

$$
\begin{gathered}
\theta=\frac{P_{i}}{\mathrm{NTU}_{i}}=\frac{F P_{i}}{\mathrm{NTU}_{i C}}, \\
\frac{P_{h}}{P_{c}}=\frac{\mathrm{NTU}_{h}}{\mathrm{NTU}_{c}}=\frac{1}{R_{h}}=R_{c}, \\
\frac{1}{\mathrm{NTU}_{i C}}=\frac{\left(1-R_{i}\right)}{\ln \left[\left(1-R_{i} P_{i}\right) /\left(1-P_{i}\right)\right]} .
\end{gathered}
$$

The above equations are valid provided that the heat exchanger with two inlet and two outlet streams operates in the stationary operation. The index $i$ in these equations corresponds to either the index $h$ or $c$.

However, it should be noted that the behavior of the heat exchanger is mainly determined by the weaker stream. It is a stream whose heat capacity $\left(\bar{C}_{p}\right)$ has a smaller value. This is then denoted by the subscript $\min$ (or 1), i.e., $\bar{C}_{p \min }=\bar{C}_{p 1}=\min \left\{\bar{C}_{p h}, \bar{C}_{p c}\right\}$. The second stream, whose heat capacity is larger, has then the subscript max (or 2). For these reasons, in the literature, it can be seen that the index $i$ in Eqs. (1) to (3) corresponds to either the index $\min$ or max (1 or 2$)$.

By combining the Eqs. (1) and (2), the general equation can be obtained:

$$
\frac{1}{\mathrm{NTU}_{i}}=\frac{F\left(1-R_{i}\right)}{\ln \left[\left(1-R_{i} P_{i}\right) /\left(1-P_{i}\right)\right]} .
$$

Any recuperative heat exchanger with two inlet and two outlet streams must comply with this equation.

According to [13], [14], the stationary operation of a recuperative heat exchanger with two inlet and two outlet streams is usually described by any combination of the three variables (except for variable $\mathrm{NTU}_{i C}$ ) appearing in the Eq. (1). The variable $\mathrm{NTU}_{i C}$ is used less often in the description. This represents a limit case, because for each heat exchanger, according to [5], [14], the following equation applies: $\mathrm{NTU}_{i C}=F . \mathrm{NTU}_{i}$. It is, therefore, possible to write:

$$
\mathrm{f}\left(\mathrm{NTU}_{i}, P_{i}, R_{i}\right)=0 .
$$

This equation represents the functional dependence used within the $\varepsilon$-NTU method, on the basis of which the graphical and analytical dependencies are constructed describing the stationary operation of the heat exchanger. An example is the equations given in the Tab. 1, as well as Fig. 1, or data given in the form of tables - Tab. 2. Fig. 2 shows the functional dependence $P_{i}=\mathrm{f}\left(\mathrm{NTU}_{i}, R_{i}\right)$ constructed on the basis of the data given in Tab. 2. These figures document the fact that each heat exchanger can be presented by a different method, each of which has its own advantages and disadvantages. 
Tab. 1 Dimensionless temperature change of a given heat exchanger $(\varepsilon)$ [7].

Heat exchanger with parallel flow

$$
\begin{aligned}
& \varepsilon=\frac{1-\exp [-\mathrm{NTU}(1+R)]}{1+R} \\
& \varepsilon=\frac{1-\exp [-\mathrm{NTU}(1-R)]}{1-\operatorname{Rexp}[-\mathrm{NTU}(1-R)]}
\end{aligned}
$$

Heat exchanger with countercurrent flow

1-2 heat exchanger (one shell-side pass, even number of tube-side passes)

$$
\varepsilon=\frac{2}{(1+R)+\sqrt{R^{2}+1} \frac{1+\exp \left(-\mathrm{NTU} \sqrt{R^{2}+1}\right)}{1-\exp \left(-\mathrm{NTU} \sqrt{R^{2}+1}\right)}}
$$

$n$ - $2 n$ heat exchanger $(n$ shell-side passes, $2 n, 2 n+2,2 n+4$, etc. tube-side passes)

$\varepsilon=\frac{\left(1-\varepsilon_{a} R\right)^{n}-\left(1-\varepsilon_{a}\right)^{n}}{\left(1-\varepsilon_{a} R\right)^{n}-R\left(1-\varepsilon_{a}\right)^{n}}$

where $\varepsilon_{a}$ is calculated as in 1-2 heat exchanger with NTU $=\mathrm{NTU} / n$

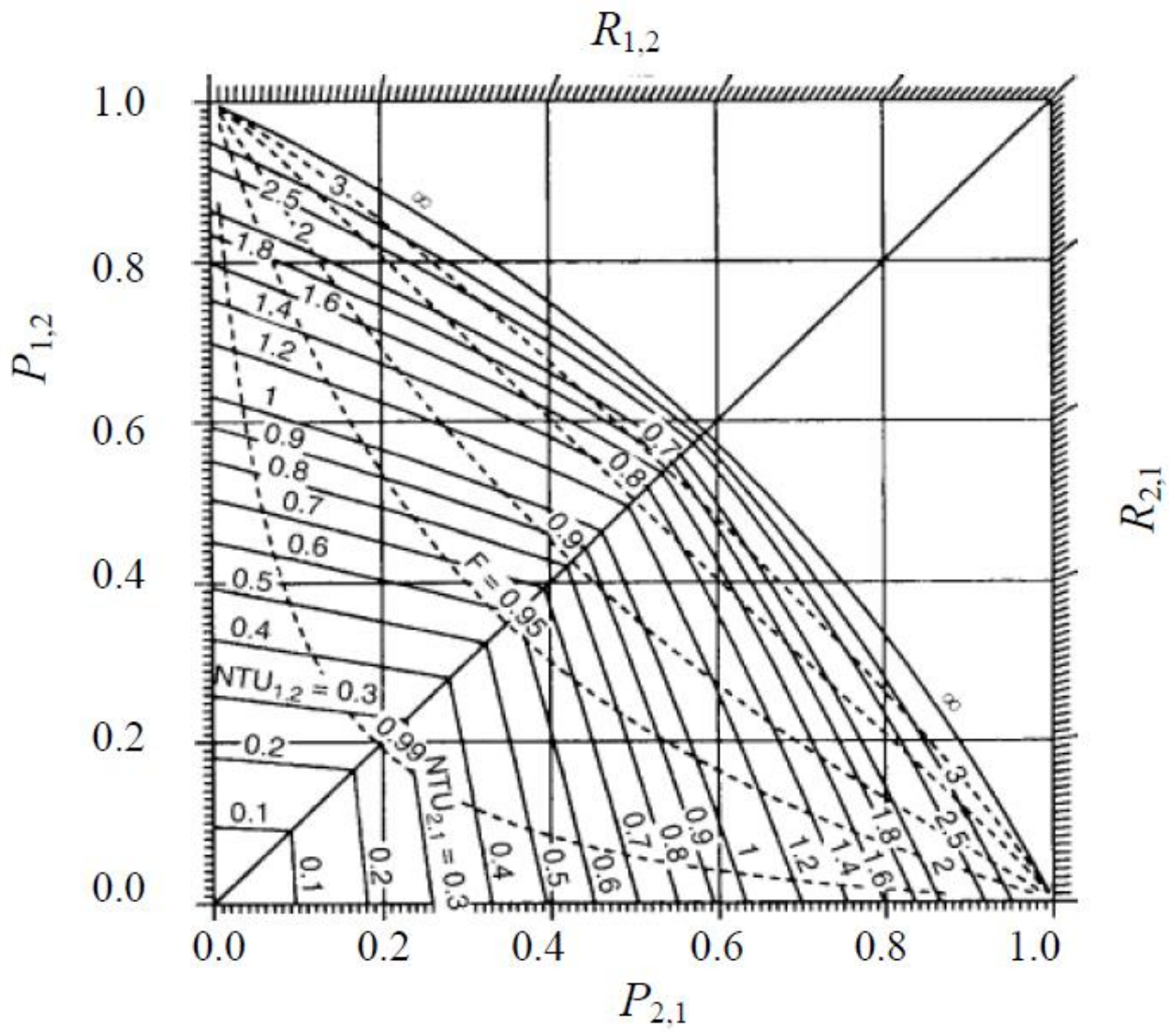

Fig. 1 Shell and tube heat exchanger with one shell-side and two tube-side passes [5]. 
Tab. 2 Dimensionless temperature change $\left(P_{\min }\right)$ of 1-2 shell and tube heat exchanger with fluid mixing on the shell-side [6].

\begin{tabular}{|l|l|l|l|l|l|l|l|l|l|l|l|}
\hline $\begin{array}{c}R_{\min } \\
\mathrm{NTU}_{\min }\end{array}$ & 1.000 & 0.900 & 0.800 & 0.700 & 0.600 & 0.500 & 0.400 & 0.300 & 0.200 & 0.100 & 0.000 \\
\hline 0.500 & 0.324 & 0.331 & 0.337 & 0.343 & 0.350 & 0.357 & 0.364 & 0.371 & 0.378 & 0.386 & 0.394 \\
\hline 1.000 & 0.463 & 0.477 & 0.492 & 0.507 & 0.523 & 0.540 & 0.557 & 0.575 & 0.593 & 0.612 & 0.632 \\
\hline 1.500 & 0.526 & 0.547 & 0.568 & 0.591 & 0.614 & 0.638 & 0.664 & 0.691 & 0.718 & 0.747 & 0.777 \\
\hline 2.000 & 0.557 & 0.581 & 0.607 & 0.634 & 0.663 & 0.693 & 0.725 & 0.758 & 0.792 & 0.828 & 0.865 \\
\hline 2.500 & 0.572 & 0.598 & 0.627 & 0.658 & 0.690 & 0.724 & 0.760 & 0.797 & 0.836 & 0.876 & 0.918 \\
\hline 3.000 & 0.579 & 0.607 & 0.638 & 0.670 & 0.704 & 0.741 & 0.780 & 0.820 & 0.862 & 0.906 & 0.950 \\
\hline 3.500 & 0.582 & 0.612 & 0.643 & 0.677 & 0.713 & 0.751 & 0.791 & 0.834 & 0.878 & 0.923 & 0.970 \\
\hline 4.000 & 0.584 & 0.614 & 0.646 & 0.680 & 0.717 & 0.756 & 0.798 & 0.842 & 0.887 & 0.934 & 0.982 \\
\hline
\end{tabular}

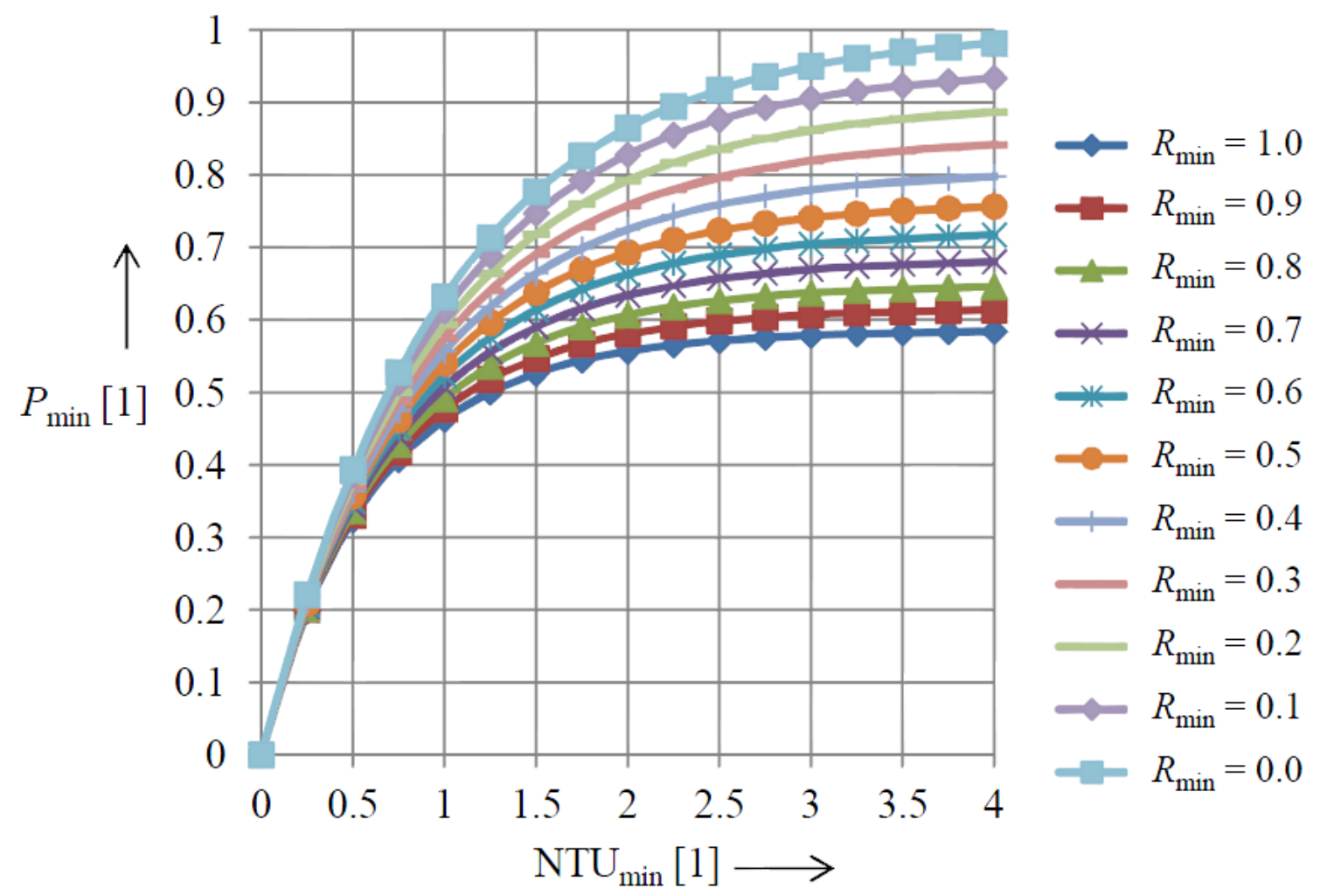

Fig. 2 The dependence of $P_{\min }$ on NTU $\mathrm{Nin}_{\text {min }}$ for 1-2 shell and tube heat exchanger with fluid mixing on the shell-side, the parameter of the curves is $R_{\min }$.

By comparing some analytical dependencies compiled in accordance with the Eq. (5), it can be found that these are strikingly similar. The scientific community [15], [16] [17] has responded to this fact resulting in the following equation:

in which

$$
\mathrm{NTU}_{1}=\frac{1}{Z} \ln \left[\frac{2-\left(1+R_{1}-Z\right) P_{1}}{2-\left(1+R_{1}+Z\right) P_{1}}\right],
$$

$$
Z=\sqrt{\left(1+R_{1}\right)^{2}-4 p_{p} R_{1}}
$$

In this equation, the subscript 1 pertains to variables representing a weaker flow (i.e., $\mathrm{NTU}_{1}=\mathrm{NTU}_{\min }, R_{1}=R_{\min }$, and $P_{1}=P_{\text {min }}$ ) [18]. It follows from the previous one (see Eq. (5)) that the stationary operation of any recuperative heat exchanger can be described 
by the variables $\mathrm{NTU}_{i}, P_{i}$, and $R_{i}$. This then means that $p_{p}$ in Eq. (6) is the variable that distinguishes the type of heat exchanger - the flow arrangement of the streams. The value of this variable is in the range from 0.0 to 1.0 (i.e., $p_{p} \in\langle 0.0 ; 1.0\rangle$ ). The limit values represent the double-tube heat exchanger with cocurrent flow $\left(p_{p}=0.0\right)$ and the double-tube heat exchanger with countercurrent flow $\left(p_{p}=1.0\right)$. If $p_{p}=0.5$, then in this case it is 1-2 shell and tube heat exchanger with fluid mixing on the shell-side.

The specific value of the variable $p_{p}$ is determined by the Eq. (6) and by the variables values $\mathrm{NTU}_{i}, P_{i}$, and $R_{i}$ representing the given operating state of the heat exchanger. If the operating states are expressed by other variables, then these must be converted to the values of the variables $\mathrm{NTU}_{i}, P_{i}$, and $R_{i}$. The relationships mentioned above, or mentioned e.g., in [5], [13], [14], [19], can be used for conversion.

\section{The determination of the countercurrent index value}

The determination of the countercurrent index value $\left(p_{p}\right)$ is relatively simple. The value of the variable $p_{p}$ based on Eq. (6) can be assigned to each operating state which is characterized by the variables $\mathrm{NTU}_{i}, P_{i}$, and $R_{i}$. The set of $p_{p}$ values which is necessary to analyze is thus obtained. If the set of $p_{p}$ shows no signs of the functional dependence and the $p_{p}$ values are not very different from each other, the values obtained in this way are simply averaged to obtain the mean value of the countercurrent index. On the other hand, it is necessary to look for the functional dependence by which the influence of the given dimensionless variables on the value of the countercurrent index is described.

The procedure for determining the value of countercurrent index $\left(p_{p}\right)$ for a given recuperative heat exchanger is as follows:

1. The values of the variables representing the given operating states of the heat exchanger are obtained. In this case, it will be data given in Tab. 2 .

2. Based on Eq. 6, the values of the variable $p_{p}$ will be determined separately for each operating state of the heat exchanger (i.e., for each $i$-th triplet of the values $P_{\min }, R_{\min }$, and $\mathrm{NTU}_{\min }$ listed in Tab. 2, the $i$-th value of the variable $p_{p}$ is obtained, see Tab. 3). The $p_{p}$ value is determined so that the condition $\Delta P_{\min }=P_{\min c}-P_{\min l} \leq 3.10^{-4}$ is fulfilled (i.e., $P_{\min }$ is determined with precision to three decimal places). The relative error for $P_{\min }$ is identified based on the values showed in Tab. 3 (i.e., for each $i$-th value of $p_{p}$, a relative error is determined in terms of the relation $\delta=\frac{P_{\min c}-P_{\min l}}{P_{\min l}}$ ). Next, the overall value of the absolute values of the relative errors (i.e., $\delta_{o}=\sum_{i=1}^{i=n}\left|\delta_{i}\right|$, where $n=88.0)$ is determined. This is represented by the value $1.348 \%\left(\delta_{o}=1.348 \%\right)$.

3. The mean value of the countercurrent index is determined as the arithmetic mean of the $n$-th values of $p_{p}$ obtained in step 2 (i.e., $p_{p}=\frac{\sum_{i=1}^{i=n} p_{p i}}{n}$ ). In this case, $p_{p}=0.499 \cong 0.50$. The graphical dependence $p_{p}=\mathrm{f}\left(\mathrm{NTU} \mathrm{U}_{\min }\right)$ (Fig. 3) can also be constructed to better assess the constancy of the countercurrent index (see also the values listed in Tab. 3).

4. For completeness, the relative error $(\delta)$ is also determined for the case where $P_{\text {min }}$ is determined for each operating state of the heat exchanger on the basis of the mean value of $p_{p}$ given in step 3 . The overall value of the absolute values of the relative errors (i.e., $\left.\delta_{o}=\sum_{i=1}^{i=n}\left|\left(\frac{P_{\min c}-P_{\min l}}{P_{\min l}}\right)_{i}\right|, n=88.0\right)$ is in this case represented by the value $3.454 \%$. Fig. 4 documents that this is a negligible value. In this figure, the data obtained from the literature (i.e., $\left.P_{\min l}\right)$ are compared with the data (i.e., $P_{\min }$ ) determined 
by calculation using Eq. 6, in which $p_{p}=0.50$. It follows from the above in this case, that $p_{p} \cong 0.50$ can be considered as a constant in a given range of values.

Tab. 3 Countercurrent index $\left(p_{p}\right)$ for individual operating states of 1-2 shell and tube heat exchanger with fluid mixing on the shell-side.

\begin{tabular}{|l|l|l|l|l|l|l|l|l|l|l|l|}
\hline $\begin{array}{c}R_{\min } \\
\mathrm{NTU}_{\min }\end{array}$ & 1.000 & 0.900 & 0.800 & 0.700 & 0.600 & 0.500 & 0.400 & 0.300 & 0.200 & 0.100 & 0.000 \\
\hline 0.500 & 0.481 & 0.531 & 0.508 & 0.470 & 0.495 & 0.511 & 0.515 & 0.498 & 0.460 & 0.550 & 0.502 \\
\hline 1.000 & 0.504 & 0.500 & 0.500 & 0.492 & 0.495 & 0.500 & 0.495 & 0.501 & 0.486 & 0.464 & 0.494 \\
\hline 1.500 & 0.496 & 0.501 & 0.497 & 0.503 & 0.499 & 0.494 & 0.498 & 0.502 & 0.492 & 0.497 & 0.497 \\
\hline 2.000 & 0.500 & 0.499 & 0.500 & 0.498 & 0.500 & 0.499 & 0.501 & 0.502 & 0.500 & 0.501 & 0.499 \\
\hline 2.500 & 0.502 & 0.498 & 0.499 & 0.502 & 0.501 & 0.501 & 0.503 & 0.500 & 0.501 & 0.500 & 0.500 \\
\hline 3.000 & 0.501 & 0.499 & 0.502 & 0.500 & 0.498 & 0.500 & 0.502 & 0.500 & 0.499 & 0.506 & 0.500 \\
\hline 3.500 & 0.498 & 0.501 & 0.499 & 0.501 & 0.501 & 0.500 & 0.499 & 0.503 & 0.502 & 0.499 & 0.500 \\
\hline 4.000 & 0.499 & 0.500 & 0.500 & 0.498 & 0.499 & 0.498 & 0.500 & 0.502 & 0.499 & 0.501 & 0.499 \\
\hline
\end{tabular}

Tab. 3 is a key output of the above procedure for determining $p_{p}$. It provides the data without which it would not be possible to calculate a given recuperative heat exchanger. Having such a table for a given heat exchanger is the same as having data about the key variables $F, \mathrm{NTU}_{\min }$, or $\theta$. Therefore, it can be stated that $p_{p}$ is also the key variable without which the Eq. 6 would be inapplicable. If the values of $p_{p}$ are known, this equation is a convenient alternative to the common methods used to describe the heat exchangers.

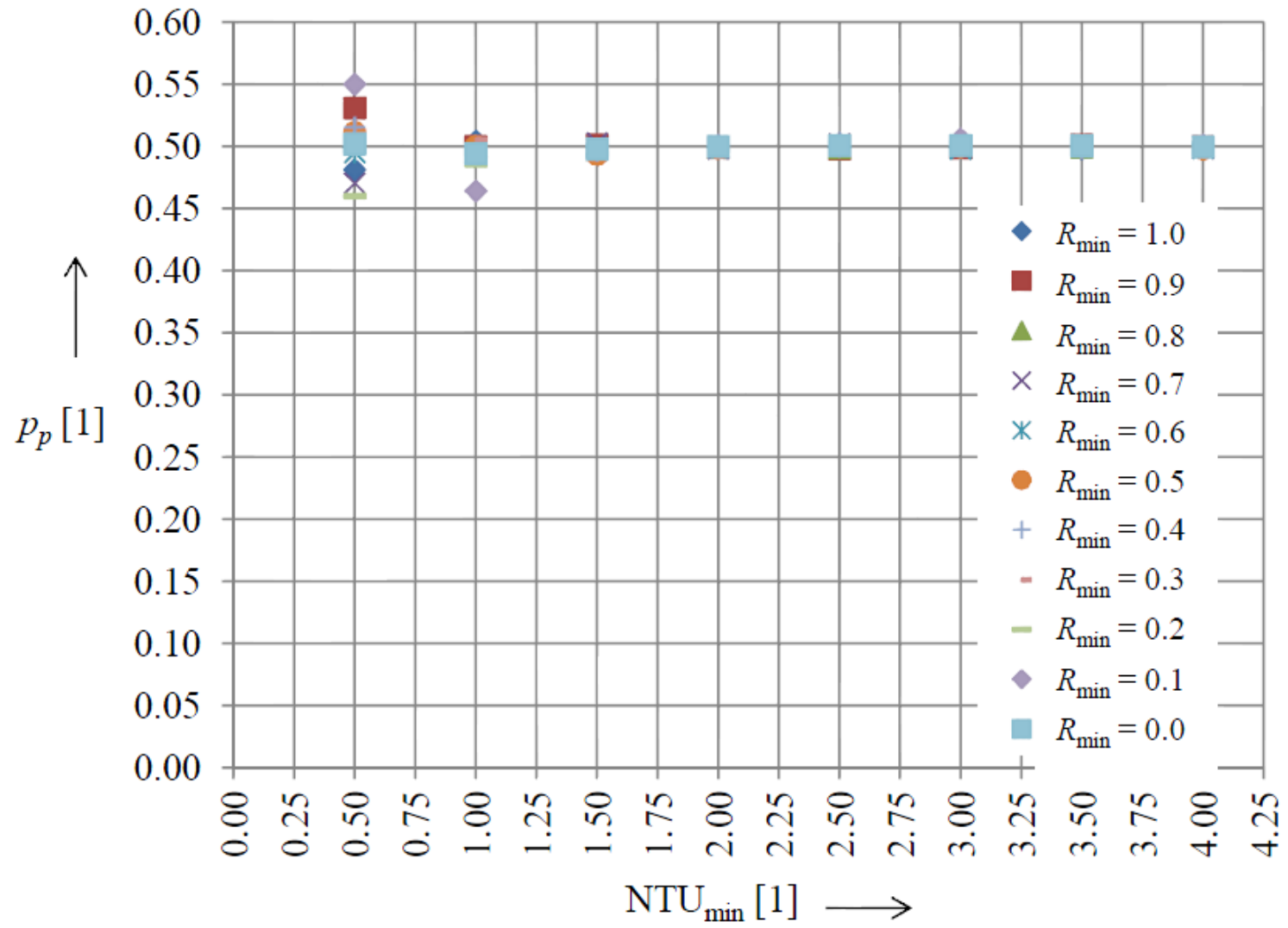

Fig. 3 The dependence of $p_{p}$ on $\mathrm{NTU}_{\text {min }}$ for 1-2 shell and tube heat exchanger with fluid mixing on the shell-side. 


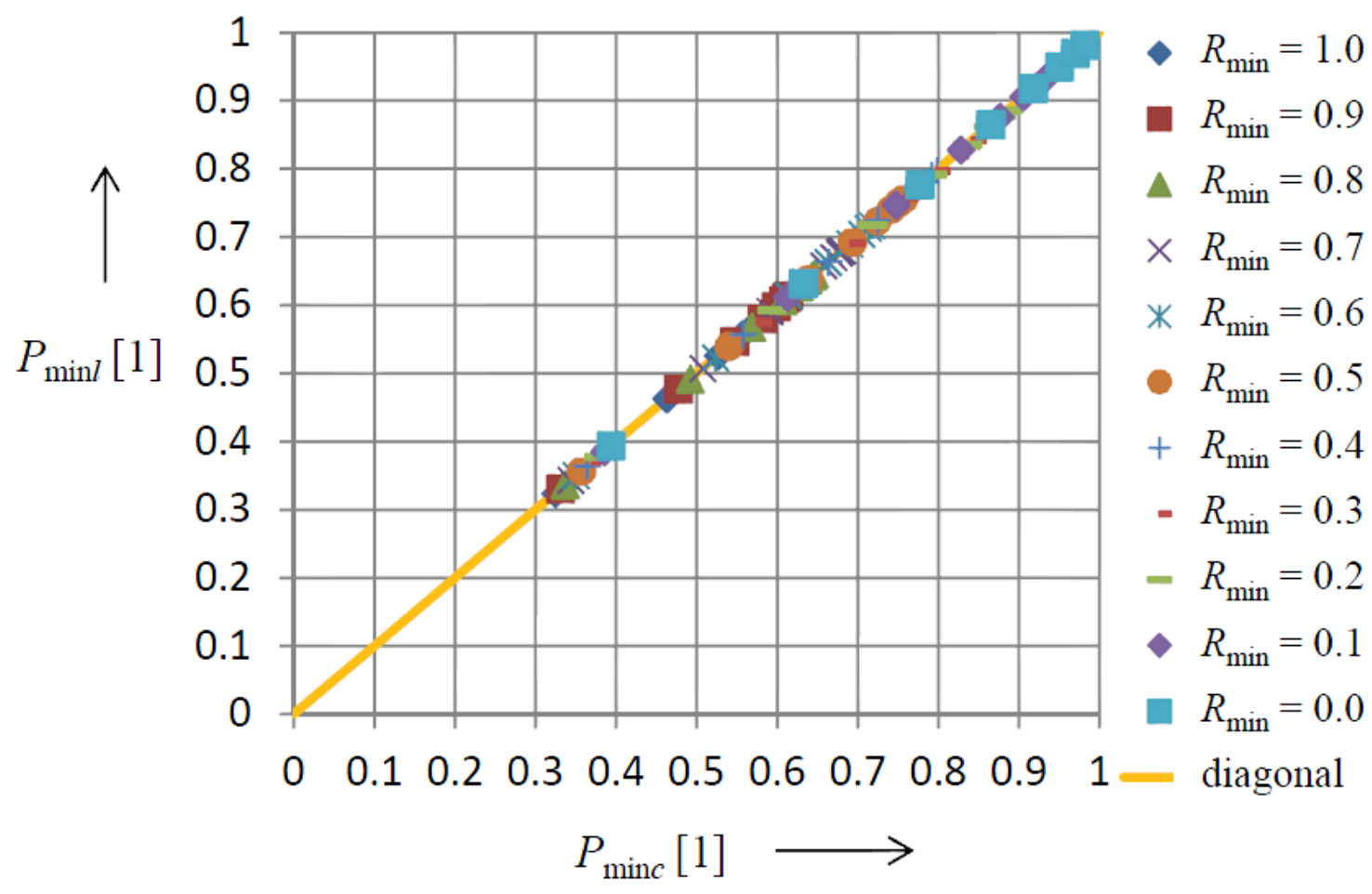

Fig. 4 The dependence $P_{\min l}$ on $P_{\min c}$ for 1-2 shell and tube heat exchanger with fluid mixing on the shell-side.

The last thing that can be said, the functional dependence $\delta_{o}=\mathrm{f}\left(p_{p}\right)$ can be used for a quick assessment of whether the countercurrent index $\left(p_{p}\right)$ will show signs of functional dependence. In this functional dependence, the overall value of the absolute values of the relative errors (i.e., $\delta_{o}=\sum_{i=1}^{i=n}\left|\delta_{i}\right|$, where $n=88.0$ ) is determined for any possible value of the countercurrent index. If such a functional dependence is constructed, then it will have a local minimum (Fig. 5). This minimum characterizes the certain values of the variables $p_{p}$ and $\delta_{o}$. If $\delta_{o}$ approaches zero, $p_{p}$ can be considered as a constant value for a given heat exchanger. The value thus determined should not differ significantly from the mean value specified in step 3 of the procedure for determining the value of the countercurrent index. Fig. 5 confirms this fact that in the case of this heat exchanger, $p_{p}=0.5$. 


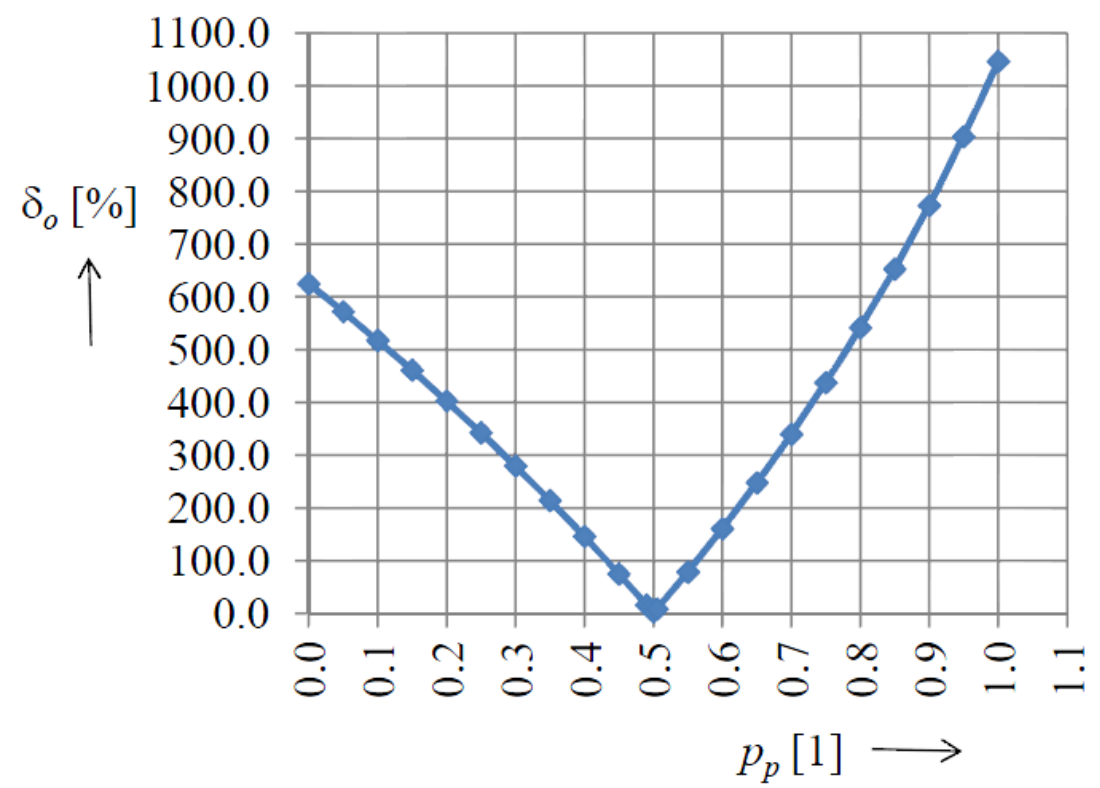

a) The overall behavior of the function $\delta_{o}=\mathrm{f}\left(p_{p}\right)$.

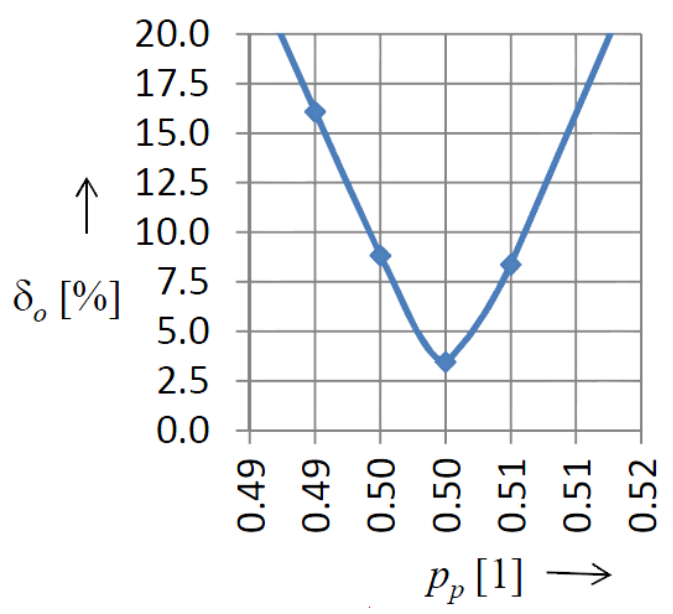

b) The detail of the local minimum.

Fig. 5 The dependence $\delta_{o}$ on $p_{p}$ for 1-2 shell and tube heat exchanger with fluid mixing on the shell-side.

\section{CONCLUSION}

The main purpose of the article is to point out the fact that there is a general functional dependence which can be used to describe the individual operating states of a given heat exchanger. This dependence differs from other operating characteristics in that it works with the variable $p_{p}$. Countercurrent index $\left(p_{p}\right)$ can also be considered as a key variable because without it the heat exchanger calculation would not be possible to perform. Determining the value of this variable is relatively simple, as is documented in this article. Therefore, if possible, it is suitable to try to assign this variable to a given heat exchanger. This variable can be presented either in the form of tabular data or by a certain average value with which the calculation can be performed with reasonable accuracy. However, the relevant data of the variables $\mathrm{NTU}_{i}, P_{i}$, and $R_{i}$ describing the given operating states of the recuperative heat exchanger must be available for the correct determination of the countercurrent index $\left(p_{p}\right)$. The description of the heat exchanger by means 
of the variable $p_{p}$ has the advantage that the functional dependence, which makes it possible to describe the operation of the heat exchanger with sufficient accuracy, is known in advance.

\section{ACKNOWLEDGEMENTS}

This research did not receive any specific grant from funding agencies in the public, commercial, or not-for-profit sectors.

\section{NOMENCLATURE}

Latin Letters

$\begin{array}{llcl}C_{p} & \text { - heat capacity flow rate at constant } & P & \text { - dimensionless temperature } \\ & \text { pressure [W/K] } & & \text { change [1] } \\ \text { NTU } & \text { - number of transfer units [1] } & p_{p} & - \text { countercurrent index [1] } \\ F & \text { - logarithmic mean temperature } & R & - \text { heat capacity rate ratio [1] } \\ & \text { difference correction factor [1] } & Z & - \text { auxiliary parameter [1] } \\ \text { Greek Letters } & & \\ \delta \quad \text { - relative error [\%] } & \Phi & \text { - heat efficiency [1] } \\ \varepsilon \quad \text { - dimensionless temperature } & \theta & \text { - dimensionless mean temperature } \\ \quad \text { change [1] } & & \text { difference [1] }\end{array}$

Subscripts

c - cold medium, calculated value $\quad \min$ - weaker stream, minimum

$C$ - pure countercurrent flow $n$ - number of data

$h$ - hot medium o - total

$i \quad-i$-th medium, $i$-th operating state $\quad-\quad-$ mean value

$l \quad-$ value from the literature $\quad 1$ - weaker stream

max - stronger stream, maximum $\quad 2$ - stronger stream

\section{REFERENCES}

[1] Bowman R. A., Mueller A. C., Nagle W. M. "Mean temperature difference in design", 62, ASME Transaction, 1940.

[2] Kays W. M., London A. L. "Compact heat exchangers", 2nd ed., New York: McGrawHill Book Co., 1964.

[3] Mueller A. C., in Rohsenow W. M. and Hartlett J. P. "Handbook of heat transfer", Sec. 18, Heat exchangers, pp. 1 -113, New York: McGraw-Hill, 1973.

[4] Roetzel W., Spang B. "Vefbessertes Giagramm zur Berechnung von Wänneüberttragern”, pp. 259 - 264, Wärme-unf Stoffübertragung, 25, 1990.

[5] "VDI Heat Atlas", Second Edition, Springer-Verlag Berlin Heidelberg, 2010. ISBN 978-3-540-77876-9

[6] Hlavačka, V. “Termická účinnost výměníků tepla, Technické příručky 1”, PraheBěchovice, SVÚSS, 1988.

[7] Cao, E. "Heat Transfer in process Engineering", The McGraw-Hill, 2010. ISBN 978-007-162613-2.

[8] Teke I., Ağra Ö., Demir H., Atayılmaz Ş. Ö. "Sizing, Selection, and comparison of heat exchangers considering the lowest saving-investment ratio corresponding to the area at 
the tag end of the heat exchanger", Energy 78, pp. 114 - 121, 2014. DOI:10.1016/j.energy. 2014.08.035.

[9] Cabezas-Gómez L., Saiz-Jabardo J. M., Navarro H. A., Barbieri P. E. L. "New thermal effectiveness data and formulae for some cross-flow arrangements of practical interest", International Journal of Heat and Mass Transfer 69, pp. 237 - 246, 2014. DOI: 10.1016/j.ijheatmasstransfer.2013.10.022

[10] Navarro H. A., Cabezas-Go'mez b L. "A new approach for thermal performance calculation of cross-flow heat exchangers", International Journal of Heat and Mass Transfer 48, pp. 3880 - 3888, 2005. DOI: 10.1016/j.ijheatmasstransfer.2005.03.027

[11] Vasconcelos Segundo E.H.d., Mariani V. C., Coelho L.d.S. "Design of heat exchangers using Falcon Optimization Algorithm", Applied Thermal Engineering 156, pp.119 144, 2019. DOI: $10.1016 /$ j.applthermaleng.2019.04.038

[12] Schneller J., Hlavačka V. "Význam termickej účinnosti při výpočtech jednoduchých i složitějších teplosměnných systémů”, Strojírenství 6 (22), 1972.

[13] Jelemenský K., Šesták J., Žitný R. “Tepelné pochody”, 2. vydanie, Vydavatel'stvo STU v Bratislave, 2004. ISBN 80-227-2109-3.

[14] Gužela Š., Dzianik F. "Some Facts Resulting from the Key Variables Used in the Description of the Recuperative Heat Exchangers", Strojnícky časopis - Journal of Mechanical Engineering 68 (3), pp. 249 - 260, 2018. DOI:10.2478/scjme-2018-0038

[15] Belokon N. N. “Analitičeskije osnovy teplovogo rasčeta trubčatych pečej”, Neftjanaja promyšlennost', 1941.

[16] Kanavec G. E. "Universal'nyj metod rasčeta konečnych temperatur potokov v teploobmennych apparatach", Inst. gaza AN USSR, Kijev, 1973.

[17] Trefny F. "Wärmeaustausch bei beliebiger Stromart”, Chemie-Ing.-Techn., 1965.

[18] Gužela Š., Dzianik F. "The Recuperative Heat Exchangers - The Mean Temperature Difference in the Special Cases of Heat Transfer", Strojnícky časopis - Journal of Mechanical Engineering 70 (1), pp. 47 - 56, 2020. DOI: 10.2478/scjme-2020-0005

[19] Gužela Š., Dzianik F., Juriga M., Kabát J. "Shell and Tube Heat Exchanger - the Heat Transfer Area Design Process", Strojnícky časopis - Journal of Mechanical Engineering 67 (2), pp. 13 - 24, 2017. DOI:10.1515/scjme-2017-0014 